\section{Benjamin y la teoría de lo sublime tecnológico}

\author{
Umberto Roncoroni
}

N avegando en la abundante literatura dedicada a la cultura digital, se tiene la impresión de encontrarse dentro de un mundo de fantasmagorías utópicas y futuristas, donde parecen crearse o destruirse identidades, significados y hábitos sociales. Luego, si se miran los procesos y los resultados concretos en la comunicación, en la producción artística o en la educación, las hipérboles desaparecen sin dejar huellas y se regresa a una realidad mucho más banal. Algunas de estas novedades simplemente no encuentran aplicaciones significativas (fuera de algunos nichos muy especializados) como es el caso de la realidad virtual, pero muchas veces se trata de verdaderas marchas atrás, como bien indican los alternos acontecimientos de la new economy.

En realidad, las instancias más vistosas de la cibercultura son consecuencia y efecto de procesos que la tecnología simplemente ha enfatizado y acelerado, pero no generado. Los cambios que se deberían atribuir al medio digital son mucho más estructurales y profundos, y no aparecen en la pantalla mediática de la industria cultural. Sucede que es fácil observar los fenómenos digitales desde una perspectiva y con instrumentos que no permiten diferenciar lo que es accesorio de lo que es estructural. Desde esta perspectiva, que Sherry Turkle ha definido como la dimensión de la interfaz, no se puede salir de las metáforas y los verdaderos problemas quedan irresueltos. 
En esta ocasión propongo demostrar que uno de los orígenes de semejantes distorsiones interpretativas está en las antiguas cuestiones estéticas y filosóficas, que a pesar de todo siguen siendo de actualidad, porque están resueltas solo en apariencia. Estos viejos problemas tienen importante influencia en la creatividad, el arte y la educación, que hasta ahora parecen recibir más impedimentos que ayudas de las tecnologías de la información (excepto, naturalmente, beneficios de orden económico o productivo). Como dice Turkle: "The possibilities of using this thing poorly so outweigh the chance of using it well, it makes people like us, who are fundamentally optimistic about computers, very reticent". 1

\section{El aura y el digital}

El marco conceptual de la crítica tecnológica tiene raíces lejanas: sus padres intelectuales (Adorno, Benjamin, Heidegger...) pertenecen a una o más generaciones anteriores a la de los sur- fers y los hackers. Se piensa que un contexto tan acelerado y tan diferente ("ovejas azules", cyborgs, hiperrealismo virtual, etcétera) no pueda ser discutido y comprendido basándose en problemas, cuestiones y fundamentos que se han originado en la Europa de la posguerra. Pero es solamente dentro de la dimensión de la interfaz que se puede creer que la tecnología digital represente un corte con este pasado y, por ende, que sus acontecimientos sean revolucionarios. En efecto, sus procesos radican en la ingeniería de la máquina de la revolución industrial y sus arquitecturas son de orígenes totalmente analógicos. Por esto, el único modo que todavía tenemos para leer el digital es la comparación con tecnologías más antiguas, como la fotografía o la televisión, que brindan, además, los únicos antecedentes teóricos. ${ }^{2}$

Uno de estos es la teoría de la reproducibilidad técnica y del aura de Benjamin, un contexto teórico, a decir de algunos críticos y filósofos, superado y que sería hasta un impedimento para el desarrollo de cuestiones más

1 Citado en OPPENHEIMER, Todd. "The computer delusion". Atlantic Monthly 1, 1997.

2 Vale recordar que As we may think de Vannevar Bush es de 1945, y de 1903 lo que escribió Edward Steichen en Camera Work: "Some day there may be invented a machine that needs but to be wound up and sent roaming o'er hill and dale, through fields and meadows, by babbling brooks and shady woods; in short, a machine that will discriminatingly select its subject and by means of skilful arrangements of springs and screws, compose its motifs, expose the plate, develop, print and even mount and frame the results of its excursion, so that there will remain nothing for us to do but to send it to the Royal Photographic Society's exhibition and gratefully to receive the Royal Medal" (STIEGLITZ, Alfred. Camera work. The complete illustrations 1903-1917, 1997). 
serias y actuales. ${ }^{3}$ Naturalmente, desde Benjamin han cambiado muchas cosas. Con respecto al arte y a la comunicación, podríamos destacar dos eventos en particular: en primer lugar, la evolución nihilista del pensamiento posmoderno, que acaba con las ideologías o los grandes relatos, pone varias cuestiones de epistemología acerca de la ciencia y del método y termina discutiendo el mismo concepto de progreso y de historia; y en segundo lugar, naturalmente, la informática, las redes, las simulaciones y la virtualidad. Por estas instancias filosóficas, la relación entre forma, belleza y verdad se disuelve (y con ellas el modernismo), y se marca el paso desde la crítica benjaminiana y situacionista al postestructuralismo de Barthes y a los simulacros de Baudrillard. En lugar de aura y artista se prefiere hablar de mass-media, y en lugar de reproducibilidad técnica, de técnicas de producibilidad y, como hace Mario Costa, ${ }^{4}$ de "sublime tecnológico".

\section{Lo sublime y la tecnología}

Por sublime tecnológico Costa entiende la unión del sublime posmoderno de Lyotard con la dimensión desconocida, incierta y amenazante propia de las nuevas tecnologías digitales. A ver: la lectura posmoderna de lo sublime se refiere no tanto a lo sublime romántico de matriz kantiana, cuanto a la dimensión difuminada y sin fundamentos filosóficos seguros (metafísica o meta-narratives), que hemos heredado del nihilismo de Nietzsche y de Heidegger. La estética de la condición posmoderna, entonces, rompe el enlace entre arte, belleza y una verdad que no existe en forma estable y prefiere ubicarse dentro de este maelstrom que es la incertidumbre, la interpretación, el fragmento, el collage, el reciclaje; en suma, el arte de la posvanguardia, que con la forma y la belleza no tiene nada que ver. Lo tecnológico constituye la otra faceta de lo sublime porque, según Costa, la autónoma proliferación de las ciencias aplicadas o de la tecnociencia produce una distancia progresivamente mayor entre los conocimientos tecnológicos y la comprensión de sus instancias por los mortales comunes.

Pero en la teoría de Costa hay otra idea importante, lo que cierra el círculo de su razonamiento acerca del aura: con las herramientas digitales se supera el concepto de reproducibilidad (típico de la técnica analógica de Benjamin) para entrar en la dimensión de la 'producibilidad'. Esta, según Costa, nace por dos factores: uno, porque el

3 PISCITELLI, Alejandro. Ciberculturas 2.0, 2002.

4 COSTA, Mario. "For a new kind of aesthetics". 7th Generative Art Conference Proceedings, 2005. 
digital elimina en modo definitivo las diferencias entre original y copia, así que no hay reproducibilidad sino clonación, creación iterativa de infinitos originales; dos, porque las herramientas digitales pueden producir obras de modo autónomo, utilizando tecnologías como la programación genética, la vida e inteligencia artificial y las nuevas matemáticas de la complejidad, del caos y de los sistemas dinámicos.

Aquí la producibilidad implicaría sobre todo la eliminación del referente real en el proceso de creación y de comunicación. Los textos sintéticos no necesitan ser relacionados estructuralmente con la naturaleza; en este sentido no son propiamente mímesis, sino una nueva especie de realidad. Por ende, concluye Costa, la sola razón de hacer arte es para explorar la relación entre lo sublime y la tecnología, experimentando la producibilidad en cuanto tal más allá del significado que la obra por sí misma pueda comunicar. El artista se convierte en investigador estético, que no produce obras sino proyectos, experimentos, mapas conceptuales en forma audiovisual de lo sublime tecnológico. Sea porque no hay más que experimentos, sea porque las obras se anulan en sus clona- ciones, sea porque el autor es sustituido por la síntesis numérica, el concepto de aura se vacía definitivamente de cualquier otro residuo de sentido.

\section{Reproducibilidad, producibilidad, irreproducibilidad}

Pero las simulaciones, que parecen formas de autopoiesis o de constructivismo radical, no nacen de la nada: si el referente de la obra no es el fenómeno natural o el dato concreto, es su modelo científico y matemático tal como está incrustado en los algoritmos de las técnicas generativas. ${ }^{5}$ El bic et nunc de Benjamin, la relación con el contexto real que funda la unicidad de la obra de arte y su sentido, se vuelve modelo matemático, es decir texto e interpretación, donde completa la autorreferencia de semejantes sistemas epistemológicos.

Naturalmente, hay críticos que advierten que estas dimensiones radicalmente antirrealistas que caracterizan lo sublime tecnológico están destruyendo cualquier posibilidad de comunicación concreta con el público, con lo cual se abren las puertas a lo arbitrario, a lo humanamente insignificante y a lo psicológica, política y social-

5 Por generativo se entiende un proceso creativo que utiliza e interactúa con sistemas dinámicos simulados por computadora, sobre la base de teorías como la autopoiesis de Maturana y Varela; los fractales, los autómatas celulares y naturalmente las gramáticas generativas de Chomsky. Técnicas y tecnologías generativas se aplican al diseño industrial, a la arquitectura y a la música. 
mente superficial; en suma, el simulacro o la dimensión de la interfaz. Por ejemplo, Valentina de Angelis escribe: "La ilusión referencial, que anula la distancia entre invención y realidad es una razón estética tranquilizadora, pero falsa. (...) La referencia es tautológica, la transición desde la realidad al signo es inadvertida, la impresión de alguna correspondencia es fuerte pero totalmente irracional". 6 [Traducción del autor.]

Ahora, en los pro y los contra de lo sublime tecnológico hay implícitamente por lo menos tres premisas: a) las tecnologías de la información son tecnologías de la reproducibilidad absoluta, principalmente porque hacen desaparecer por entero las diferencias entre original y copia (desaparece el aura de unicidad de la obra); b) las herramientas digitales son capaces de creación autónoma y existe la autopoiesis o autoorganización fuera de los sistemas naturales (se pierde el bic et nunc y nace la producibilidad); c) los procesos sintéticos producen necesariamente la pérdida del sentido, la debilidad epistemológica y la imposibilidad de la interpretación (con el aura y el autor muere también el lector porque, pace Barthes, la reproducibilidad absoluta más la autopoiesis artificial no crean textos que puedan ser interpretados, sino realidades ajenas que ni siquiera pueden ser deconstruidas).
Esta perspectiva de las tecnologías digitales y de las simulaciones es, sin embargo, distorsionada e incompleta. Habría que preguntarse, antes que todo, las razones de su difusión entre los críticos y los teóricos del digital. Me parece que estas tienen raíces y orígenes en prejuicios y creencias profundamente ligados a la separación entre ciencias exactas y humanas y al problema heideggeriano de la techne y de la tecnociencia. En primer lugar, la costumbre de pensar el digital como una extensión de lo analógico, donde se confunde el hardware con el software, las interfaces con los periféricos; en suma, lo electrónico con el digital (en ambos casos se usan pantallas, asî que parecen ser la misma cosa...). Un ejemplo típico es la multimedia, una tecnología que no pertenece propiamente a la dimensión digital, que es más bien caracterizada por la homogeneidad e integridad del medio numérico.

En segundo lugar, el error de hablar del digital en el nivel de su capa física, sin considerar que las tecnologías de la información se componen esencialmente del software y sus fundamentos científicos y filosóficos (aquí está el viejo problema de las dos culturas). En este caso no se consideran las profundas relaciones entre las aproximaciones sistémicas de la teoría de la complejidad y sus fundamentos filosóficos

6 DE ANGELIS, Valentina. Arte e linguaggio nell'era elettronica, 2000, pp. 307-308. 
y estéticos (la estética hermenéutica, que comenzando por Heidegger se desarrolla en Gadamer y Vattimo).

Y por último, la mirada superficial, que ve el texto digital como producto y no como proceso, es decir, que va especulando sobre el objeto en lugar de abordar el sistema dinámico e interactivo que lo ha producido. Aquí lo que principalmente se ignoran son los mecanismos de la interacción y las implicaciones hermenéuticas de la hipertextualidad, de lo abierto, de lo emergente y de lo indeterminado.

\section{¿̇eproducibilidad o irreproducibilidad?}

De acuerdo con estos razonamientos, la producibilidad tendría sentido porque las clonaciones de los procesos de la autopoiesis tecnológica pierden su interés en cuanto objetos: la obra como acabado efectivamente desaparece y con ella, aparentemente, el problema del aura. Pero aquí hay que examinar estas dinámicas con un poco más de profundidad; el crear y el hacer obra no se anulan en absoluto, sino que cortan los respectivos enlaces románticos con la estética del genio y cambian estas dimensiones ontológicas para reubicarse en el marco con- ceptual de la inventio y en la metodología operativa de la forza di levare. ${ }^{7}$

Reconduciendo estos temas a sus instancias actuales, se pueden notar algunos mecanismos particularmente significativos. Para comenzar, la crisis de la obra nace por la contradicción entre un arbitrario estatus privilegiado del arte y de sus ismos modernistas con las instancias antimetafísicas y nihilistas de la posmodernidad. Y, por lo menos según Vattimo, ${ }^{8}$ el arte posmoderno lucha contra el sentido modernista de ser obra (el kitsch), empapándose en el flujo y en la lógica de lo efímero de la "esfera mediática". Pasados algunos años y con la difusión de las computadoras, sin embargo, se podría más bien mirar los fenómenos de la comunicación globalizada e individualizada que la internet produce (los blogs), la producción interactiva de información que salta los cercos de los medios tradicionales, y la net-Art, que en cierto modo se presentan como una alternativa al sistema de distribución y consumo de la industria cultural. En estos casos la obra de arte como objeto ejemplar o modelo universal se fragmenta y se disuelve en los infinitos procesos interactivos de las redes de comunicación, pero al mismo tiempo se reintroduce el aura,

7 Desde una famosa poesía de Miguel Ángel. Y no es el caso de que la inventio pertenece al mismo contexto humanista del artista científico, una utopía renacentista que se ha vuelto de actualidad con el reciente matrimonio entre matemáticos, ingenieros informáticos y arte.

8 VATTIMO, Gianni. "Morte o tramonto dell'arte". La fine della modernitá, 1999, p. 59. 
los bic et nunc y la unicidad dentro de los nodos de las comunicaciones individuales.

En segundo lugar, como ya dijimos, el sentido de obra y el aura no desaparecen, sino que cambian de ubicación. Si miramos desde el punto de vista operativo de la interactividad y de las nuevas ciencias de la complejidad (las aplicaciones del software, de los sistemas dinámicos, del caos, de la autoorganización, de la vida y de la inteligencia artificial), lo que parece realmente importante son los procesos. En efecto, la complejidad se compone de dinámicas emergentes: el orden es el producto de la interacción entre los diferentes elementos del sistema. Estos tienen un importante peso epistemológico, porque incluyen ciencia, diseño, estética, transformación de informaciones en conocimientos y naturalmente la interacción entre el software y los usuarios. Ahora bien, los resultados de cada proceso no son determinados a priori, la obra es entonces una construcción abierta e interactiva y por esto las instancias del sistemismo emergente son siempre diferentes e irrepetibles.

En conclusión: por los mecanismos interactivos que fragmentan el monolito de la comunicación masiva en infinitos nodos individuales y por las nuevas estéticas que nacen de la complejidad y de las simulaciones, la verdadera naturaleza del digital, su esencia, su estética es la irreproducibilidad y la unicidad. Y es solo permaneciendo en la dimensión de la interfaz o de la obra que se opera este error prospectivo que es lo sublime tecnológico.

\section{Actualidad de los problemas del aura}

Como es sabido, la reproducibilidad técnica elimina el genio pero reintroduce sus elementos constitutivos (arbitrio, individualidad, autorreferencia) a través del star system (en lugar de lo político como planteaba Benjamin). Precisamente, este mecanismo está en el origen de la industria cultural, de la transformación estética de la realidad y, por último, de los simulacros.

¿Puede replicarse esta contradicción también con las técnicas generativas, en la interacción y en las simulaciones? Por supuesto que sí; en efecto, la misma dinámica del aura y del genio que caracteriza la obra de arte romántica, que Benjamin cuestiona, a través de la reproducibilidad se recicla casi exactamente dentro de la relación entre software y usuario. Tenemos, entonces, que salir de la dimensión de la interfaz y entrar en las entrañas de los procesos digitales: se deberían empezar a discutir las dimensiones preformativas del software, el papel y la opacidad de las interfaces, los relativos problemas de transmisión del conocimiento, y, en general, las relaciones hermenéuticas que se instalan cuando se comienza un proceso creativo o 
interpretativo digital. Aquí se abren nuevos espacios para la problemática del aura y del genio, espacios que están abiertos y poco cuestionados: a) el aura del proceso (tiene un autor y un contexto), b) los mecanismos de interacción y retroalimentación entre autor y lector (cuya relación ahora es dinámica e inestable), c) la unicidad y la multiplicidad que caracterizan los hipertextos, d) el aura de la interfaz (donde se establecen las reglas entre lector y autor y el intercambio de estas experiencias), e) la validación de los bic et nunc que encontramos en los fundamentos científicos de las simulaciones y en el código de los programas.

Hay quien explora el digital en este sentido, pero claro está, fuera de la dimensión de la interfaz y lejos de los efectos especiales, de los gadgets o de la explotación juguetona de internet y del www que tanto está de moda en los festivales del tecnoarte, que lamentablemente ya están siendo reincorporados en el mainstream de la industria cultural.

\section{Bibliografía}

BENJAMIN, Walter. "The work of art in the age of mechanical reproduction". Illusions. Nueva York: Schoken, 1969.

BUSH, Vannevar. "As we may think". The Atlantic Monthly, 1945.

COSTA, Mario. "For a new kind of aesthetics". 7th Generative Art Conference Proceedings. Milán: Politecnico di Milano, 2005.

DE ANGELIS, Valentina. Arte e linguaggio nell'era elettronica. Milán: Mondadori, 2000.

OPPENHEIMER, Todd. "The computer delusion". The Atlantic Monthly. Vol. 280, núm. 1. Julio de 1997.

PISCITELLI, Alejandro. Ciberculturas 2.0. Buenos Aires: Paidós, 2002.

STEINER, George. Grammatiche della creazione. Milán: Garzanti, 2003.

STIEGLITZ, Alfred. Camera work. The complete illustrations 19031917. Simone Philippi (ed). Colonia: Taschen, 1997.

VATTIMO, Gianni. La fine della modernitá. 3. ${ }^{\text {a }}$ edición. Milán: Garzanti, 1999. 